\title{
MUL1 E3 ligase regulates the antitumor effects of metformin in chemoresistant ovarian cancer cells via AKT degradation
}

\author{
JUNWOO LEE ${ }^{1,2^{*}}$, SUNGKWAN AN $^{2^{*}}$, JIN HYUK JUNG $^{1}$, KARAM KIM $^{1}$, JI YEA KIM $^{1,2}$, \\ IN-SOOK AN $^{1}$ and SEUNGHEE BAE ${ }^{2}$ \\ ${ }^{1}$ GeneCellPharm Corporation, Seoul 05836; ${ }^{2}$ Research Institute for Molecular-Targeted Drugs, \\ Department of Cosmetics Engineering, Konkuk University, Seoul 05029, Republic of Korea
}

Received July 19, 2018; Accepted January 30, 2019

DOI: 10.3892/ijo.2019.4730

\begin{abstract}
Chemoresistance is one of most critical clinical problems encountered when treating patients with ovarian cancer, due to the fact that the disease is usually diagnosed at advanced stages. Metformin is used as a first-line drug for the treatment of type 2 diabetes; however, drug repositioning studies have revealed its antitumor effects, mainly mediated through AMP-activated protein kinase (AMPK) activation and AKT/mammalian target of rapamycin (mTOR) pathway inhibition in various types of cancer, including drug-resistant cancer cells. The current study revealed that the novel antitumor mechanism of metformin is mediated by regulation of mitochondrial E3 ubiquitin protein ligase 1 (MUL1) expression that negatively regulates AKT. The results demonstrated that metformin decreased the expression of AKT protein levels via MUL1 E3 ligase. In addition, metformin increased both mRNA and protein levels of MUL1 and promoted degradation of AKT in a proteasome-dependent manner. Silencing MUL1 expression suppressed the metformin-mediated AKT degradation and its downstream effects. Cell cycle analysis and a clonogenic assay demonstrated that knockdown of MUL1 significantly diminished the antitumor effects of metformin. Together, these data indicate that MUL1 regulates metformin-mediated AKT degradation and the antitumor effects of metformin in chemoresistant ovarian cancer cell lines.
\end{abstract}

\section{Introduction}

Ovarian cancer is one of the most lethal gynecological malignancies (1-3). It has an unfavorable prognosis, and numerous

Correspondence to: Dr Seunghee Bae, Research Institute for Molecular-Targeted Drugs, Department of Cosmetics Engineering, Konkuk University, 120 Neungdong Road, Seoul 05029, Republic of Korea

E-mail: sbae@konkuk.ac.kr

*Contributed equally

Key words: mitochondrial E3 ubiquitin protein ligase 1, metformin, AKT, ovarian cancer cells, chemoresistance, cytotoxicity of patients are diagnosed at an advanced stage, because of the absence of representative symptoms and sensitive diagnostic approaches (4). Cytoreductive surgery and postoperative adjuvant chemotherapy using platinum-based compounds and taxanes, as a single or combination treatment, have been standard for ovarian cancer (5). Therefore, chemotherapy is the inevitable therapeutic option for ovarian cancer. However, chemoresistance is a major hindrance to clinical trials for this disease. Furthermore, $\sim 75 \%$ of patients who are initially sensitive to the platinum/paclitaxel-based chemotherapy relapse due to chemoresistance, which results in therapeutic failure, causing $>90 \%$ of related deaths (6). Therefore, it is highly necessary to develop new treatment strategies against chemoresistant ovarian cancers.

Metformin has been widely used for the treatment of type 2 diabetes mellitus for decades. Metformin is a complex drug with various mechanisms of action. Previous studies have reported that metformin decreases glucose production in the liver $(7,8)$ and increases glucose utilization in the gut, altering the microbiome in the intestine and increasing glucagon-like peptide 1 secretion (9). Molecularly, the established direct target of metformin is the mitochondrial complex I in the electron transport chain, which metformin binds to and inhibits, thereby decreasing mitochondrial respiration and ATP production (10). In vivo and in vitro studies have demonstrated that metformin-induced energy depletion could activate AMP-activated protein kinase (AMPK) in the liver and hepatocytes, respectively $(11,12)$. Because AMPK serves a critical role in regulating metabolism and maintaining cellular energy homeostasis, it has been considered an important therapeutic target for controlling human diseases, including metabolic diseases and cancer (13).

Accumulating in vitro and in vivo studies have suggested that metformin has anticancer properties and, therefore, inhibits the growth of various types of cancer, including gastric, esophageal, colon and breast cancers (14-18). The primary mechanism of the antitumor effects of metformin is activating the AMPK signaling pathway. Activated AMPK activates the tumor suppressor tuberous sclerosis complex 1 and 2 (TSC1/2), which then negatively regulates mammalian target of rapamycin (mTOR). mTOR is a key mediator of phosphatidylinositol 3-kinase (PI3K)/AKT signaling, which is one of the most frequently altered pathways in 
human cancer $(19,20)$. Additionally, previous studies have demonstrated that metformin decreases the activation of AKT in several cancer cells not only via AMPK-dependent but also independent mechanisms (21-24). Although several reports suggest that metformin downregulates the PI3K/AKT pathway, many aspects of the regulatory mechanism remain unclear.

AKT, a well-known serine/threonine protein kinase, has important roles in cell survival, proliferation and tumor development (25). A previous report from our group has demonstrated that mitochondrial E3 ubiquitin protein ligase 1 (MUL1) negatively regulates AKT, through the induction of K48-linked polyubiquitination at the K284 residue (26). This polyubiquitination of AKT by MUL1 subsequently leads to its proteasomal degradation (26).

The present study demonstrated that metformin inhibited the growth of chemoresistant cancer cell lines. Furthermore, the current results revealed that metformin downregulated AKT protein expression by upregulating MUL1 E3 ligase. These findings we suggest that MUL1 may have a key role in the antitumor effects of metformin.

\section{Materials and methods}

Reagents and cell culture. Human ovarian cancer A2780 cells were purchased from the European Collection of Authenticated Cell Cultures (Salisbury, UK), while SKOV3 and paclitaxel-resistant SKOV3-TR cells were kindly provided by Dr Anil K Sood (The University of Texas MD Anderson Cancer Center, Houston, TX, USA). A2780/Cis cells were kindly provided by Professor Jae Ho Lee (Cheil General Hospital and Women's Healthcare, Seoul, Republic of Korea). The cells were maintained in RPMI-1640 medium (Thermo Fisher Scientific, Inc., Waltham, MA, USA) supplemented with $10 \%$ (v/v) fetal bovine serum (Sigma-Aldrich; Merck KGaA, Darmstadt, Germany) and 1\% (v/v) penicillin/streptomycin. All the cells were incubated in a humidified atmosphere of $5 \% \mathrm{CO}_{2}$ at $37^{\circ} \mathrm{C}$. Metformin (Sigma-Aldrich; Merck KGaA) was dissolved in phosphate-buffered saline (PBS). Human AKT serine/threonine kinase 2 (AKT2) cDNA was cloned into pcDNA3.1-Myc/His (Invitrogen; Thermo Fisher Scientific, Inc.), as previously described (26). The HA-ubiquitin (HA-Ub) plasmid pMT123 was kindly provided by Dr Dirk Bohmann (University of Rochester, Rochester, NY, USA).

Cell viability. Cells were seeded in 96-well plates ( $2 \times 10^{4}$ cells/well), and their viability was evaluated using the water-soluble tetrazolium (WST)-1 assay (EZ-Cytox cell viability assay kit; ITSBio, Seoul, Korea), according to the manufacturer's protocol. Briefly, the cells were treated with the indicated concentrations of metformin for $72 \mathrm{~h}$ and then the WST-1 solution was added to each well. The absorbance of the reaction solution was then measured at $450 \mathrm{~nm}$ with a reference wavelength of $655 \mathrm{~nm}$ using an iMark microplate reader (Bio-Rad Laboratories, Inc., Hercules, CA, USA). Proliferation was assessed using the BrdU cell proliferation assay (Cell Signaling Technology, Inc., Danvers, MA, USA), according to the manufacturer's protocol.

Immunoblotting. The protein expression levels were determined using western blot analysis. The cells were harvested and lysed in radioimmunoprecipitation assay (RIPA) lysis buffer (Thermo Fisher Scientific, Inc.), supplemented with EDTA-free protease inhibitor cocktail (Roche Diagnostics, Indianapolis, IN, USA). Total protein concentration was determined using a bicinchoninic acid (BCA) protein assay kit (Thermo Fisher Scientific, Inc.), according to the manufacturer's instruction. Then, 5X SDS sample buffer was added to each cell lysate sample, and $40 \mu \mathrm{g}$ of proteins were loaded into 8-12\% SDS-PAGE gel and separated. Then, the proteins were transferred onto a nitrocellulose membrane (Whatman; Thermo Fisher Scientific, Inc.). The membrane was blocked with $5 \%$ skim milk for $1 \mathrm{~h}$ and subsequently incubated with the indicated antibodies overnight at $4^{\circ} \mathrm{C}$. After washing with Tris-buffered saline with $0.1 \%$ Tween-20 (TBST), the membranes were incubated with a horseradish peroxidase (HRP)-conjugated anti-mouse or anti-rabbit secondary antibody (Cell Signaling Technology, Inc.). Proteins were visualized using enhanced chemiluminescence (ECL) reagents (Bio-Rad Laboratories, Inc.) and detected with the ChemiDoc Touch Imaging system (Bio-Rad Laboratories, Inc.). Anti-AMPK (cat. no. 2532), anti-phosphorylated (p-) AMPK (cat. no. 50081), anti-AKT (cat. no. 4691), anti-AKT serine/threonine kinase 1 (AKT1; cat. no. 2967), anti-AKT2 (cat. no. 5239), anti- AKT serine/threonine kinase 3 (AKT3; cat. no. 4059), anti-p-AKT (S473; cat. no. 9271), anti-glycogen synthase kinase $3 \beta$ (GSK3 $\beta$; cat. no. 9315), anti-p-GSK3 $\beta$ (cat. no. 9323), anti-Cyclin D1 (cat. no. 2922), anti- $\beta$-actin (cat. no. 4967) and anti-Myc-tag (cat. no. 2272) antibodies were purchased from Cell Signaling Technology, Inc. Anti-MUL1 (cat. no. HPA026837) antibody was purchased from Sigma-Aldrich (Merck KGaA). Anti-HA-tag antibody (cat. no. SC-7392) was purchased from Santa Cruz Biotechnology, Inc. (Dallas, TX, USA). The primary antibodies were diluted to $1: 1,000$ in TBST. The secondary anti-mouse $\operatorname{IgG}$ (cat. no. 7076) and anti-rabbit IgG (cat. no. 7074) were purchased from Cell Signaling Technology, Inc., and diluted to 1:5,000 in TBST. The intensity of each protein band (normalized to $\beta$-actin) was quantified using ImageJ software (version 1.6.0; National Institute of Health, Bethesda, MD, USA).

\section{Reverse transcription-quantitative polymerase chain reaction} $(R T-q P C R)$. Total RNAs were isolated the TRIzol reagent (Invitrogen; Thermo Fisher Scientific, Inc.). Reverse transcription was performed to synthesize cDNA with $1 \mu \mathrm{g}$ of total RNA using 1X First-Strand buffer, $10 \mathrm{mM}$ DTT, $10 \mathrm{U} / \mu 1$ Moloney Murine Lukemia Virus (M-MLV) Reverse Transcriptase, $2 \mathrm{U} / \mu 1$ RNaseOUT Recombinant Ribonucleaase Inhibitor (all from Invitrogen; Thermo Fisher Scientific, Inc.), $0.5 \mathrm{mM}$ dNTP Mix (Takara Bio Inc, Shiga, Japan), and 100 pmol oligo(dT) primer (Bionics, Seoul, Republic of Korea). The reaction mixture $\left(20 \mu \mathrm{l}\right.$ ) was incubated for $50 \mathrm{~min}$ at $37^{\circ} \mathrm{C}, 15 \mathrm{~min}$ at $70^{\circ} \mathrm{C}$ and then held at $4^{\circ} \mathrm{C}$. qPCR was performed using the StepOnePlus system (Thermo Fisher Scientific, Inc.). Each reaction $(20 \mu \mathrm{l})$ was performed using EvaGreen dye-based 1X HOT FIREPol EvaGreen qPCR Mix Plus (Solis BioDyne, Tartu, Estonia), $1 \mu \mathrm{l}$ of RT product and $10 \mathrm{pmol} / \mu 1$ primers. The reaction was incubated at $12 \mathrm{~min}$ at $95^{\circ} \mathrm{C}$, followed by 40 cycles at $95^{\circ} \mathrm{C}$ for $15 \mathrm{sec}, 50^{\circ} \mathrm{C}$ for $30 \mathrm{sec}$ and $72^{\circ} \mathrm{C}$ for $30 \mathrm{sec}$. Relative quantification of MUL1 expression was calculated according to the $2^{-\Delta \Delta \mathrm{Cq}}$ method (27) and normalized by an endogenous internal 
control ( $\beta$-actin) expression. The primers used were as follows: $\beta$-actin, 5'-GGA TTC CTA TGT GGG CGA CGA-3' (forward) and 5'-CGC TCG GTG AGG ATC TTC ATG-3' (reverse); and MUL1, 5'-CAC AAG ATG GTG TGG AAT CG-3' (forward) and 5'-TCA GCA TCT CCT CGG TCT CT-3' (reverse).

RNA interference (RNAi). SKOV3-TR and A2780/Cis cells were transfected with 100 pmol of MUL1 small interfering RNA (siRNA; Bioneer, Corporation Daejeon, Korea) using Lipofectamine RNAiMAX (Invitrogen; Thermo Fisher Scientific, Inc.). The sense sequence of MUL1 siRNA was 5'-GGGAUUUUUAUCUCGAGGC-3'. RNAi targeting MUL1 was delivered to the cells using a lentivirus encoding MUL1 short hairpin (sh) RNA as previously described (26).

In vivo ubiquitination assay. In vivo ubiquitination assays were performed as previously described (26). SKOV3-TR and A2780/Cis cells were transfected with Myc/His-tagged AKT2 and HA-tagged ubiquitin and treated with metformin for $48 \mathrm{~h}$. Then the cells were treated with proteasome inhibitor MG132 for $6 \mathrm{~h}$ prior to cell lysis. The cells were gathered, washed and lysed in $200 \mu \mathrm{l}$ of denaturing lysis buffer $(50 \mathrm{mM}$ Tris- $\mathrm{HCl}$ $\mathrm{pH} 7.4,0.5 \%$ SDS and $70 \mathrm{mM} \beta$-mercaptoethanol) by vortexing and boiling for $15 \mathrm{~min}$ at $95^{\circ} \mathrm{C}$. The lysates were diluted with $800 \mu \mathrm{l}$ buffer $\mathrm{A}\left(50 \mathrm{mM} \mathrm{NaH}_{2} \mathrm{PO}_{4}, 300 \mathrm{mM} \mathrm{NaCl}\right.$, and $10 \mathrm{mM}$ imidazole, $\mathrm{pH}$ 8.0) containing protease inhibitor cocktail and MG132. Diluted lysates were incubated overnight at $4^{\circ} \mathrm{C}$ with Ni-NTA beads (Qiagen GmbH, Hilden, Germany), which have an affinity for proteins carrying a His tag. The beads were washed five times with buffer $\mathrm{B}\left(50 \mathrm{mM} \mathrm{NaH} \mathrm{PO}_{4}, 300 \mathrm{mM}\right.$ $\mathrm{NaCl}$, and $20 \mathrm{mM}$ imidazole, $\mathrm{pH}$ 8.0). Bound proteins were eluted by boiling in SDS-PAGE sample buffer. Eluted proteins were immunoblotted with anti-HA antibody for determination of ubiquitination levels of AKT2.

Cell cycle analysis. The cells were harvested with trypsin, fixed in $70 \%$ cold ethanol overnight at $4^{\circ} \mathrm{C}$, and then stained with propidium iodide (PI) solution for $1 \mathrm{~h}$ in the dark at $37^{\circ} \mathrm{C}$. The cell pellets were washed with PBS, and the cellular DNA content was analyzed using a BD FACSCalibur flow cytometry platform (BD Biosciences, San Jose, CA, USA). Cell cycle fractions were quantified using the Cell Quest software (BD Biosciences).

Clonogenic assay. The cells were seeded at $1.5 \times 10^{3}$ cells/well in six-well cell culture plates and incubated for $24 \mathrm{~h}$. After $72 \mathrm{~h}$ exposure to $20 \mathrm{mM}$ metformin, the cells were washed and the medium was replaced with fresh medium. Then, the cells were incubated for another 14 days, and the cell colonies were stained with $0.1 \%$ crystal violet solution. The colonies on random area of each well were counted, and the results were quantified using Image $\mathbf{J}$ software (National Institutes of Health, Bethesda, MD, USA).

Statistical analysis. All data are presented as mean \pm standard deviation from triplicate experiments. Results were analyzed for statistical significance using GraphPad Prism version 5 (GraphPad software, Inc., San Diego, CA, USA) with the Student's t-test or one-way ANOVA followed by Tukey's test. $\mathrm{P}<0.05$ was considered to indicate a statistically significant difference.

\section{Results}

Metformin has anticancer activity against chemoresistant ovarian cancer cell lines. Previous studies have reported that metformin inhibits chemoresistant cancer cell growth, including that of the ovarian cancer cell lines, SKOV3-TR and A2780/cis $(28,29)$. The present study further examined the in vitro cell growth inhibition and antiproliferative effects of metformin on parental and chemoresistant ovarian cancer cell lines, in specific SKOV3 and SKOV3-TR, and A2780 and A2780/cis. First, confluency changes following metformin treatment were investigated. Consistent with previous studies, metformin decreased cell confluency in all the cell lines tested in a concentration-dependent manner (Fig. 1A and C). In addition, $20 \mathrm{mM}$ metformin significantly inhibited the growth of SKOV3 and SKOV3-TR cells in a time-dependent manner (Fig. 1B). A similar result was observed in A2780 and A2780/cis cells (Fig. 1D). The effect of metformin on cell viability and proliferation was further evaluated. SKOV3, SKOV3-TR, and A2780, A2780/cis cells were treated with various concentrations of metformin for $48 \mathrm{~h}$. The WST-1 assay demonstrated that cell viability was significantly decreased in all cell lines in a concentration-dependent manner (Fig. 1E and G). Furthermore, as shown in Fig. 1F and $\mathrm{H}$, the proliferation of all cell lines was inhibited in a concentration-dependent manner following exposure to metformin for $48 \mathrm{~h}$. These data demonstrated that metformin had anticancer activity not only on the parental but also on the chemoresistant ovarian cancer cell lines. Thus, the underlying mechanism of metformin was further investigated in the present study using these two cell lines, SKOV3-TR and A2780/cis.

Metformin decreases AKT expression in a proteasome-dependentmanner in parental and chemoresistant ovarian cancer cell lines. The anticancer effect of metformin has been previously reported to be mediated by regulation of AKT signaling in various types of cancer (21-24). Therefore, the present study sought to determine if metformin regulated the activation of AKT in parental SKOV3 and A2780, and chemoresistant SKOV3-TR and A2780/cis cells. To this end, SKOV3-TR and A2780/cis cells were treated with $20 \mathrm{mM}$ metformin for $72 \mathrm{~h}$. As illustrated in Fig. 2A and B, metformin significantly decreased p-AKT (Ser473) expression in both cell lines. Although previous studies have demonstrated that metformin increases the phosphorylation of AMPK and regulates the PI3K/AKT pathway in an AMPK-dependent manner (21,30), a significant difference in p-AMPK (Thr472) expression was not observed in the present study. Thus, the mRNA and protein expression levels of the AKT subfamily members, AKT1, AKT2 and AKT3, were examined. Notably, among the AKT family of proteins, the expression levels of AKT2 were significantly decreased following metformin treatment (Fig. 2A and B), but the mRNA expression levels of the $A K T$ family members were not changed (data not shown). Consistent with these data, metformin was demonstrated to also decrease AKT2 protein levels in parental SKOV3 and A2780 cells (Fig. 2C and D). Therefore, it was hypothesized that metformin regulated AKT expression levels post-translationally. To investigate the difference in AKT degradation following metformin exposure (effect on AKT2 
A

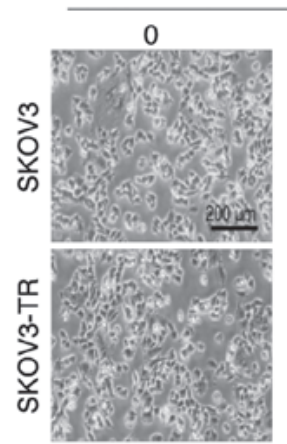

C
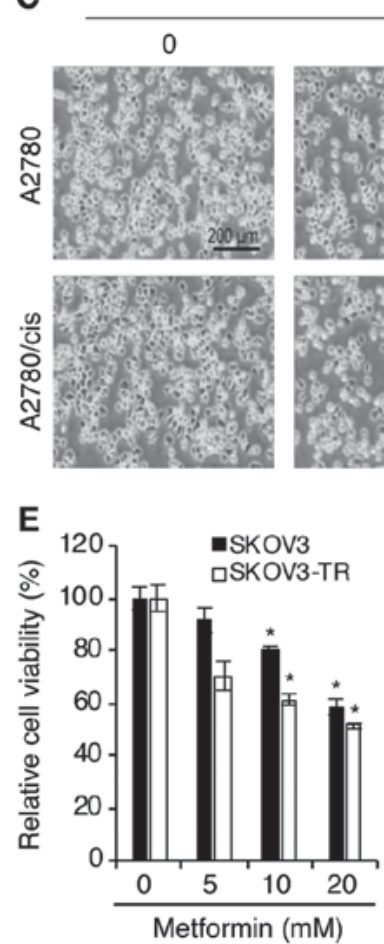

Metformin (mM)

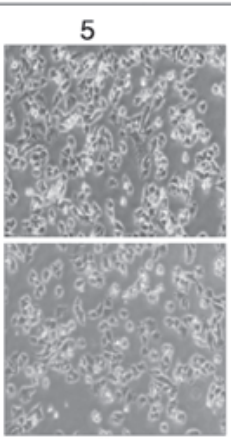

Metformin (mM)

5
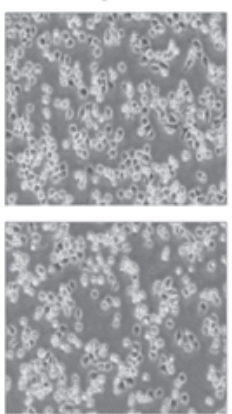

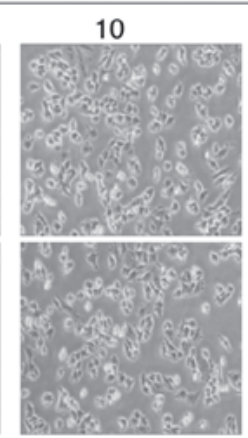

10
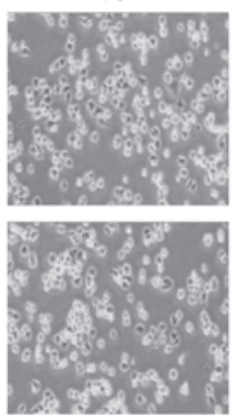

$\mathbf{F}$

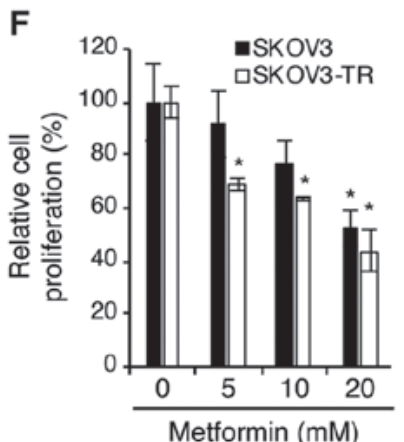

20

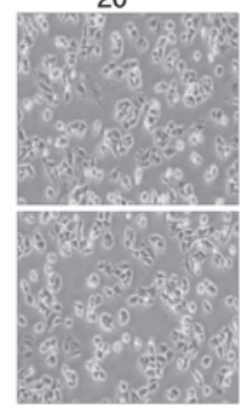

20
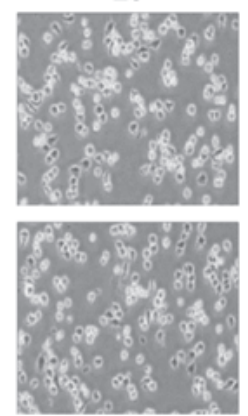

B

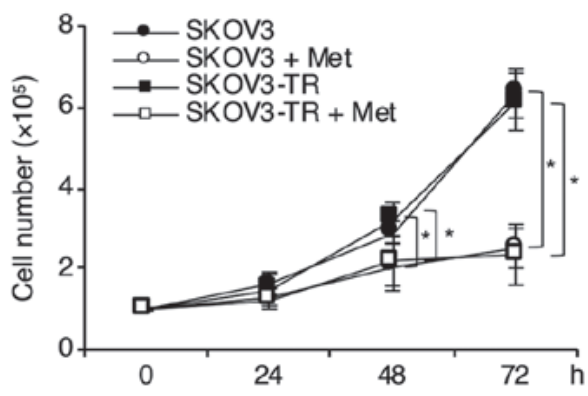

D
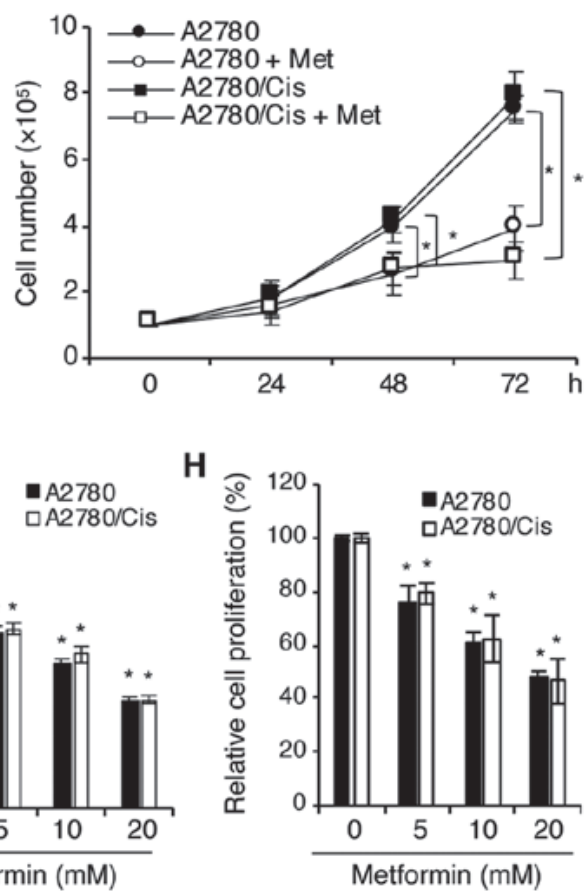

Figure 1. Metformin inhibits cell growth in both parental and chemoresistant ovarian cancer cell lines. (A) Parental SKOV3 and resistant SKOV3/TR cells were treated with indicated concentrations of metformin for $72 \mathrm{~h}$ and subsequently observed using phase contrast microscopy. (B) The number of viable cells was counted using a hemocytometer every $24 \mathrm{~h}$ for a total of $72 \mathrm{~h}$, following treatment with $20 \mathrm{mM}$ metformin. (C) Parental A2780 and resistant A2780/cis cells were treated with indicated concentrations of metformin for $72 \mathrm{~h}$ and subsequently observed using phase contrast microscopy. (D) The number of viable cells was counted using a hemocytometer every $24 \mathrm{~h}$ for a total of $72 \mathrm{~h}$, following treatment with 20 mM metformin. (E) Cell viability by WST assay and (F) cell proliferation by BrdU assay in SKOV3 and SKOV3/TR cells. (G) Cell viability by WST assay and (H) cell proliferation by BrdU assay in A2780 and A2780/cis cells. ${ }^{*} \mathrm{P}<0.05$ compared with control group. Met, metformin.

protein degradation by metformin), SKOV3-TR and A2780/cis cells were treated with cycloheximide $(\mathrm{CHX})$ to block de novo protein synthesis following dimethyl sulfoxide (DMSO; vehicle control) or $20 \mathrm{mM}$ metformin treatment. As illustrated in Fig. 3A and B, metformin treatment significantly accelerated the protein degradation of AKT2 in both SKOV3-TR and A2780/cis cell lines. To elucidate the mechanism of metformin-induced AKT2 degradation, we then investigated whether inhibition of the proteasome-dependent protein degradation pathway could abrogate the effect of metformin on AKT2 protein stability. SKOV3-TR and A2780/cis cells were treated with the peptide aldehyde proteasome inhibitor MG132 or DMSO (vehicle control) for $12 \mathrm{~h}$ following incubation with or without metformin for $48 \mathrm{~h}$. MG132 treatment rescued the decreased protein expression of AKT2 and p-AKT induced by metformin treatment in SKOV3-TR cells (Fig. 3C). Similar results were observed in A2780/cis cells (Fig. 3D), indicating that metformin decreased AKT2 and p-AKT protein expression in a proteasome-dependent manner.

Metformin increases MUL1 expression. Previous studies have demonstrated that AKT could be degraded by MUL1 and tetratricopeptide repeat domain 3 (TTC3) via K48-linked ubiquitination in a proteasome-dependent manner $(26,31)$. Bae et al (26) have reported that MUL1 interacts with AKT1 and AKT2 through a kinase domain of AKT and preferentially degrades p-AKT. Western blot analysis revealed that metformin particularly induced the degradation of AKT2 (and p-AKT) among the three AKT isoforms (AKT1, AKT2 and AKT3; Fig. 2A and B). Therefore, the present study investigated if metformin could increase MUL1 expression. MUL1 mRNA expression levels in A2780/cis 
A Metformin

(20 mM)
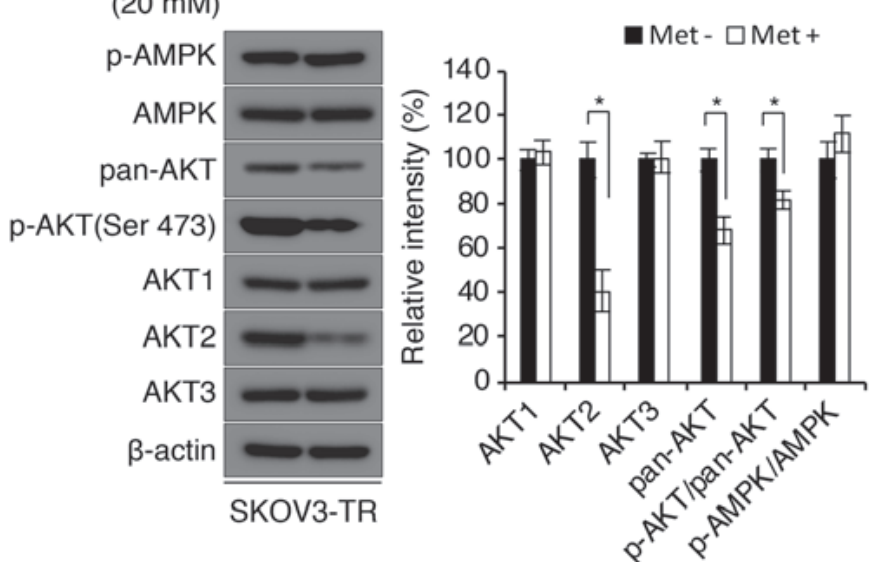

B
Metformin
$(20 \mathrm{mM})$
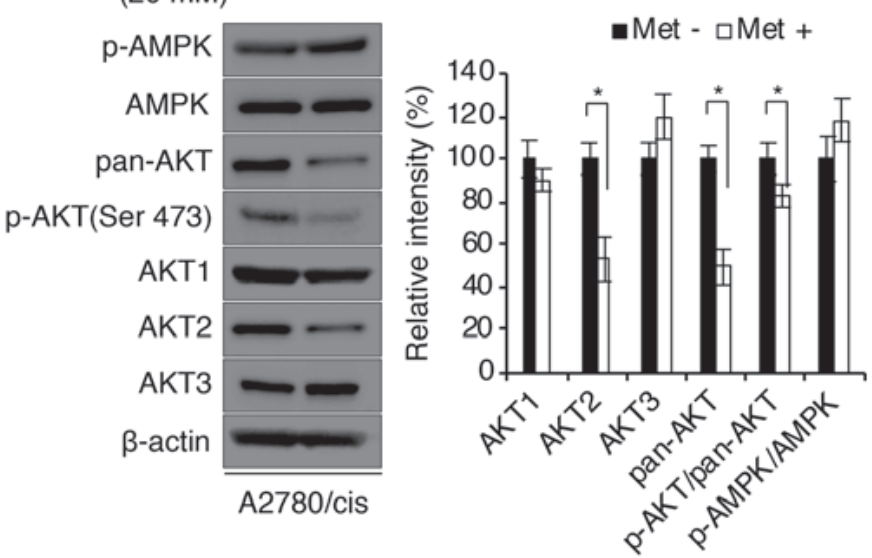
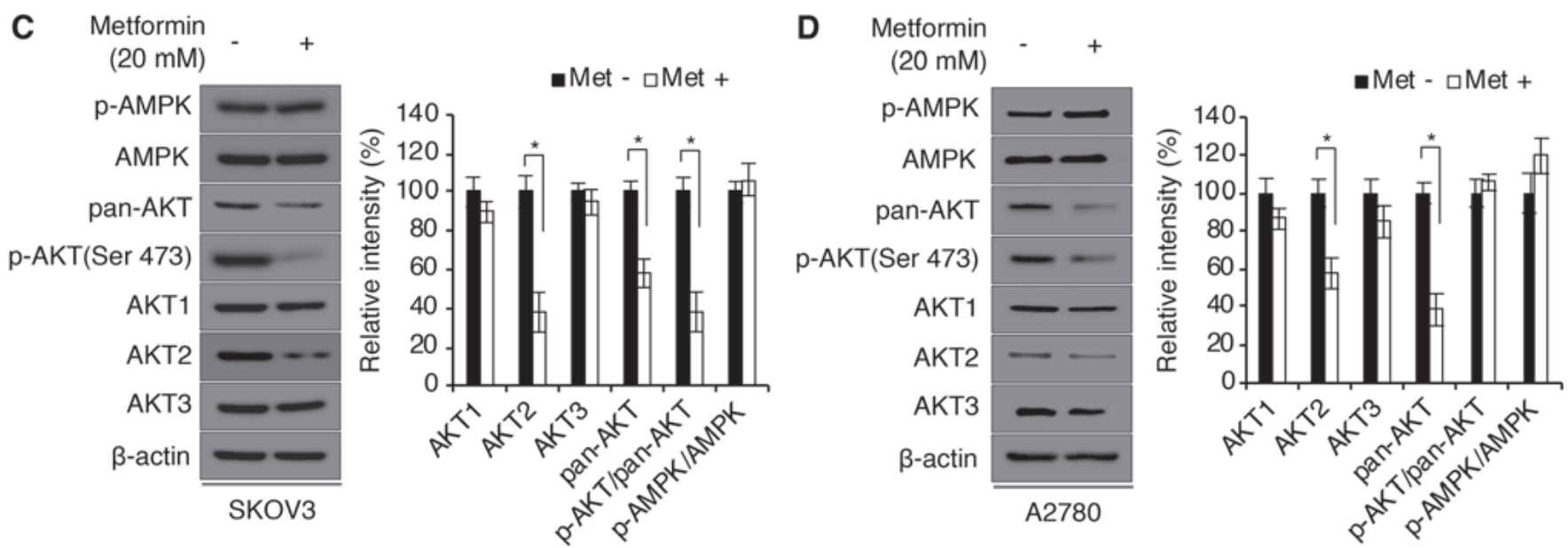

Figure 2. Metformin decreases AKT and p-AKT expression in ovarian cancer cell lines. (A) SKOV3-TR, (B) A2780/cis cells, (C) SKOV3 and (D) A2780 cells were treated with PBS or metformin $(20 \mathrm{mM})$ for $72 \mathrm{~h}$. The protein expression levels of AMPK, p-AMPK, AKT and p-AKT were determined by western blot assay. Protein levels of AKT isoforms were expressed as ratio to the mean in the control group. $\beta$-actin was used as a loading control. Samples were derived from the same experiment and gels/blots were processed in parallel. Results are presented as mean \pm standard deviation. ${ }^{*} \mathrm{P}<0.05$ compared with control. AKT, AKT serine/threonine kinase; p-, phosphorylated; AMPK, AMP-activated protein kinase; Met, metformin.

and SKOV3-TR cells treated with metformin were measured using reverse transcription-quantitative polymerase chain reaction (RT-qPCR). As shown in Fig. 4A and B, metformin treatment significantly increased MUL1 mRNA levels in A2780/cis and SKOV3-TR cells. Similarly, the protein expression levels of MUL1 were also increased following metformin treatment (Fig. 4A and B). In addition, we examined whether metformin-induced MUL1 expression was specific to the chemoresistant cells. As illustrated in Fig. 4C and D, treatment with metformin significantly upregulated MUL1 mRNA and protein expression in the parental SKOV3 and A2780 cells. Together, these findings indicate that metformin treatment enhanced both mRNA and protein expression levels of MUL1.

Metformin-induced MUL1 expression promotes AKT degradation in a proteasome-dependent manner and regulates the AKT downstream pathway. The aforementioned results led to the hypothsis that metformin-induced AKT degradation may be mediated by MUL1. To test this hypothesis, His-ubiquitin pull-down assays were performed. As illustrated in Fig. 5A and B, exposure to metformin induced polyubiquitination of AKT, and siRNA directed against MUL1 abrogated metformin-induced AKT ubiquitination in both SKOV3-TR and A2780/cis cell lines. As metformin decreased the viability and proliferation of chemoresistant ovarian cancer cell lines (Fig. 1), the effects of metformin on AKT downstream genes associated with cell cycle progression and cell growth were further examined. The GSK3//cyclin D1 pathway is a well-known downstream pathway of AKT associated with cell proliferation and cycle progression. Several reports have suggested that phosphorylation of GSK $3 \beta$ at Serine 9 by AKT decreases the kinase activity of GSK $3 \beta$ for Thr 286 of cyclin D1, which leads to the cytoplasmic proteasomal degradation of cyclin D1 $(32,33)$. Thus, in the present study the protein expression levels of p-GSK3 $\beta$ (Ser9) and cyclin D1 were determined following metformin treatment using western blot analysis. As illustrated in Fig. 5C and D, metformin treatment significantly inhibited GSK $3 \beta$ phosphorylation and cyclin D1 expression. However, knockdown of MUL1 using siRNA rescued the protein expression levels of p-AKT, AKT2, p-GSK3 $\beta$, and cyclin D1 in both cell lines. Taken together, these findings suggest that the increase in MUL1 expression induced by metformin regulated the AKT downstream pathway. 

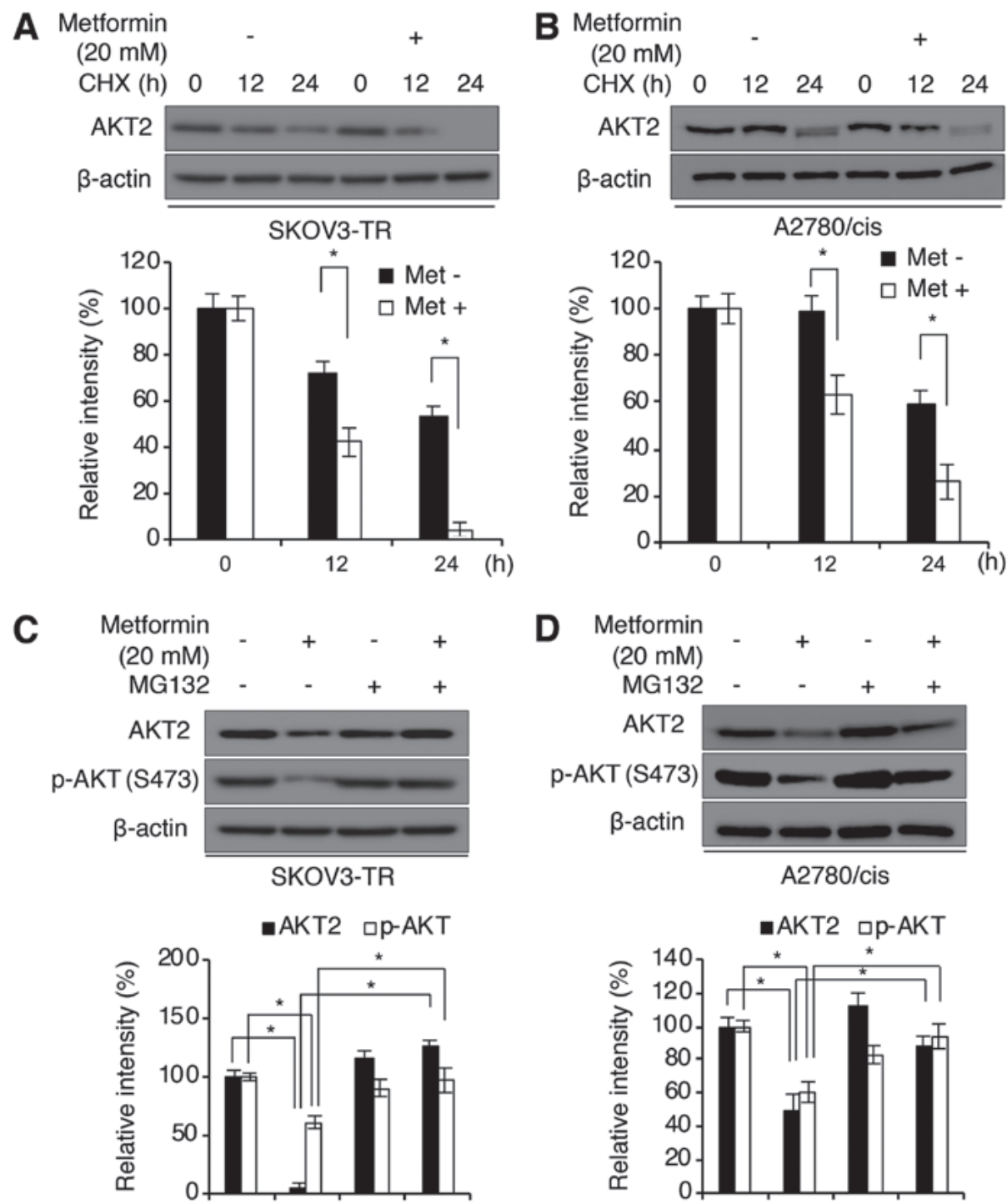

Figure 3. Metformin decreases expression levels of AKT in a proteasome-dependent manner. (A) SKOV3-TR and (B) A2780/cis cells were treated with PBS or metformin $(20 \mathrm{mM})$ and cyclohexamide and harvested at 12 and $24 \mathrm{~h}$. AKT2 stability was determined using western blot analysis. (C) Proteasome-dependent degradation inhibitor (MG132; $10 \mu \mathrm{M}$ ) rescued the expression levels of AKT2 and p-AKT reduced by metformin treatment (20 mM) in SKOV3-TR and (D) A2780/cis cell lines. $\beta$-actin was used as a loading control. Samples were derived from the same experiment and gels/blots were processed in parallel. Protein levels of AKT2 and p-AKT were expressed as ratio to the mean in the control group. Results are presented as mean \pm standard deviation. ${ }^{*} \mathrm{P}<0.05$ with comparisons indicated by brackets. AKT, AKT serine/threonine kinase; p-, phosphorylated; CHX, cycloheximide; Met, metformin.

Antitumor effects of metformin are regulated by MUL1. Next, the present study sought to determine whether the increase in MUL1 expression was required for the antitumor activity of metformin in the chemoresistant ovarian cancer cell lines. To this end, MUL1 knockdown SKOV3-TR and A2780/cis cell lines were generated, by expressing a shRNA construct targeting MUL1 (shMUL1). First, the clonogenic growth ability was investigated in the control and shMUL1 knockdown SKOV3-TR and A2780/cis cells. The results revealed that metformin treatment significantly inhibited clonogenic growth. However, the metformin-mediated inhibition of clonogenic growth was partially rescued in MUL1 stable knockdown cells, compared with the control cells (Fig. 6A and B). Because the results of Figs. 1 and 5 demonstrated that metformin treatment decreased cell viability and proliferation and downregulated the AKT/GSK3 $\beta /$ cyclin D1 pathway, which is associated with cell cycle progression, further cell cycle analyses were conducted using flow cytometry. As presented in Fig. 6C, there was a higher increase in the number of cells in the G1-phase of the cell cycle in the metformin-treated control SKOV3-TR cells compared with the metformin-treated shMUL1 SKOV3-TR cells. Similar results were observed in A2780/cis cells (Fig. 6D). Together, these data suggest that metformin-mediated MUL1 expression may be important for the antitumor activity of metformin.

\section{Discussion}

Taxane (paclitaxel) and platinum drugs (such as cisplatin) induce DNA damage and constitute the first-line chemotherapy for ovarian cancer. Unfortunately, $>70 \%$ of patients with ovarian cancer who are prescribed paclitaxel show relapse and develop chemoresistance (34). This clinical therapeutic challenge is caused by several factors. Currently, most ovarian cancers are left undiagnosed until they reach an advanced stage because there are few reliable symptoms and etiological 
A

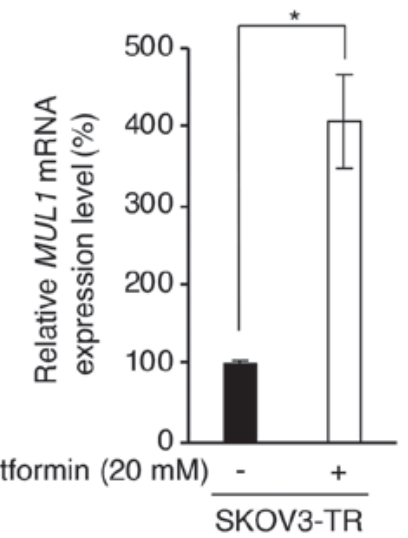

C

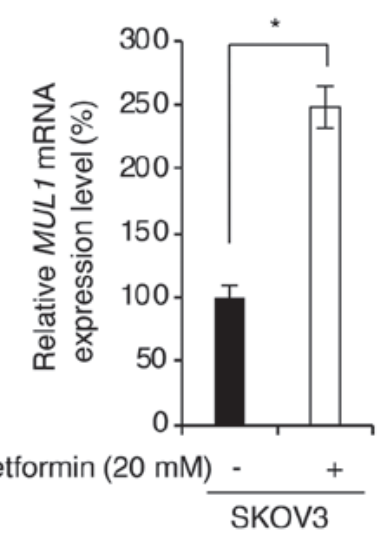

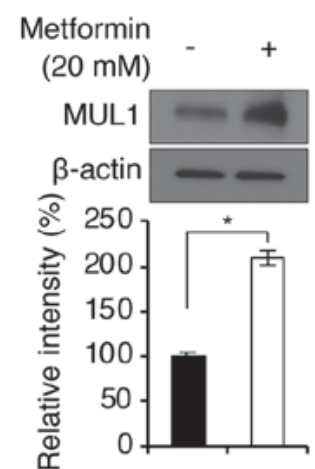

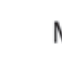

B
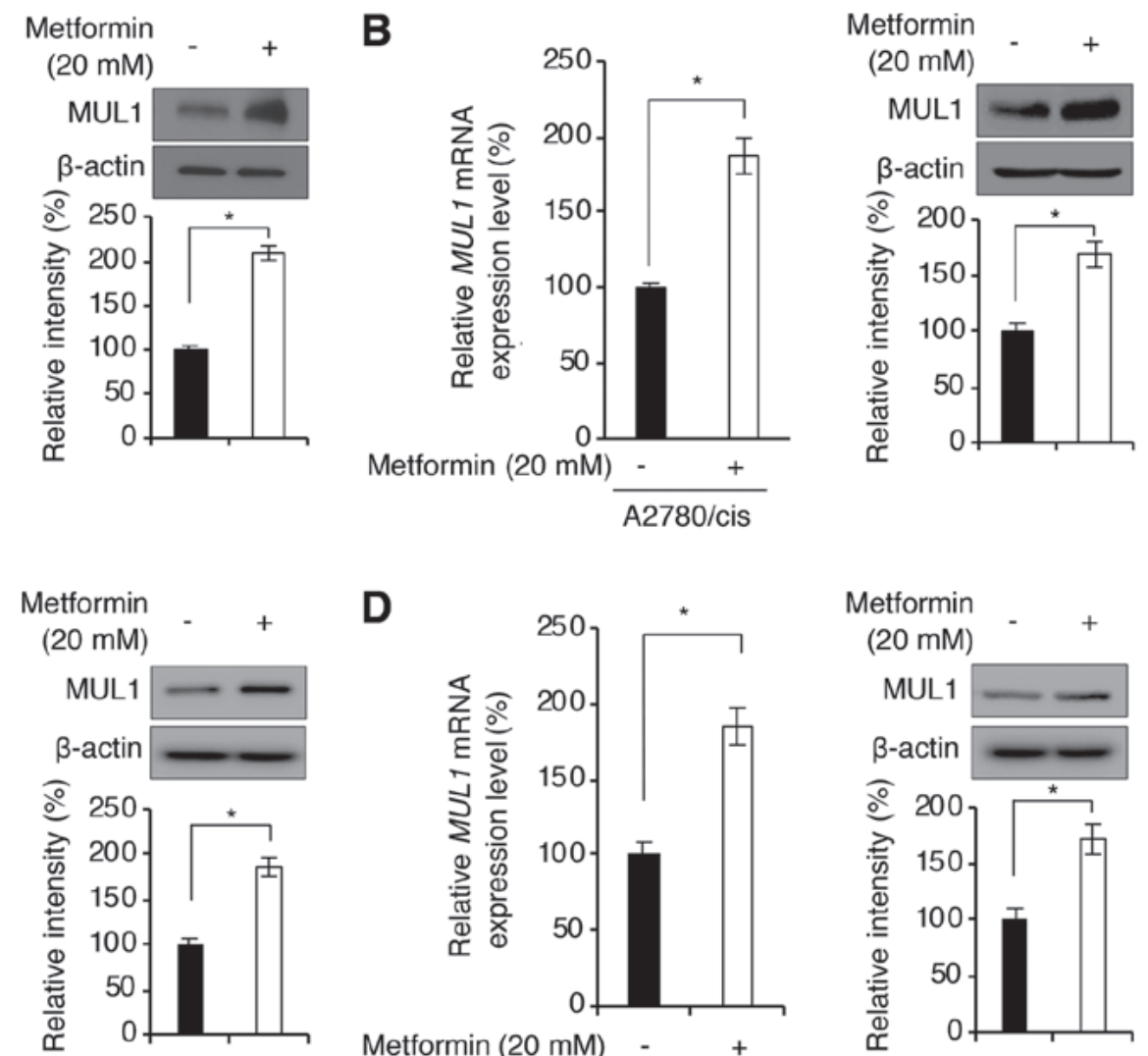

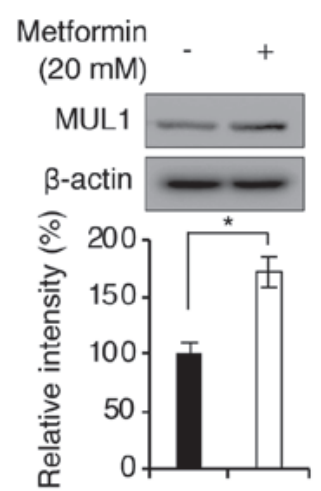

Figure 4. Metformin increases MUL1 expression. (A) SKOV3-TR, (B) A2780/cis cells, (C) SKOV3 and (D) A2780 cells were treated with 20 mM metformin for $48 \mathrm{~h}$. MUL1 mRNA and protein levels were analyzed using reverse transcription-quantitative polymerase chain reaction and western blot assays, respectively. The protein levels of MUL1 were expressed as ratio to the mean in the control group. $\beta$-actin was used as a loading control. Samples were derived from the same experiment and gels/blots were processed in parallel. Results are presented as the mean \pm standard deviation. ${ }^{*} \mathrm{P}<0.05$ with comparisons indicated by brackets. MUL1, mitochondrial E3 ubiquitin protein ligase 1.

factors in the early stages of ovarian cancer (35). Furthermore, chemoresistance is reported to be responsible for $90 \%$ of deaths in patients with advanced ovarian cancer (36). This observation indicates that chemoresistance is the primary factor in ovarian cancer relapse; however, the development of strategies targeting these chemoresistant ovarian cancers remains a fundamental challenge. These problems make ovarian cancer one of the most lethal tumors with pernicious growth and progression, frequent metastasis, and commonly acquired chemoresistance (34).

The results of the present study demonstrated the chemosensitizing effect of metformin on drug-resistant SKOV3-TR and A2780/Cis cells. Biochemical assays revealed that metformin significantly suppressed cell proliferation, viability, and cycle progression in these cells. Notably, metformin increased both mRNA and protein levels of MUL1 and promoted the degradation of AKT protein in a proteasome-dependent manner. To further analyze this, the effect of metformin on MUL1 and AKT expression was examined in the parental cell lines, SKOV3 and A2780, because data in Fig. 1 demonstrated that metformin had anticancer activity not only on the parental but also on the chemoresistant ovarian cancer cell lines. The results demonstrated that treatment with metformin decreased the level of AKT2 and significantly upregulated MUL1 expression in those cell lines, similar with the results from the SKOV3-TR and A2780/Cis resistant lines. These findings indicate that metformin-induced MUL1 expression was not a result specific to chemoresistance. AKT is known to be associated with the resistance of cancer cells to various anticancer drugs (37-41), including ovarian cancer cells (8). In addition, previous studies have demonstrated that metformin decreases the expression of p-AKT in several cancer cells. Hyperactivation of AKT, which is known to stimulate cell survival and proliferation pathways, is frequently observed in cancers. Furthermore, MUL1 has been previously demonstrated to be an E3 ubiquitin ligase for AKT1 and AKT2 (26); therefore, the present data further suggested that the chemosensitizing effect of metformin is mediated by MUL1 expression in drug-resistant ovarian cancer cells. This hypothesis was supported by the observation that silencing of MUL1 expression suppressed metformin-mediated AKT degradation and its downstream effects. Additionally, metformin significantly decreased colony formation compared with control cells; however, this inhibitory effect was suppressed by silencing MUL1 expression, indicating that MUL1 regulated metformin-mediated AKT degradation and anticancer effects in chemoresistant ovarian cancer cells. A previous study has also reported that metformin exerts a chemosensitizing effect on drug-resistant ovarian cancer cells (29). Specifically, the authors observed that metformin decreased proliferation levels with downregulation of the inflammatory signaling pathway in paclitaxel-resistant A2780 and cisplatin-resistant ACRP cell 
A

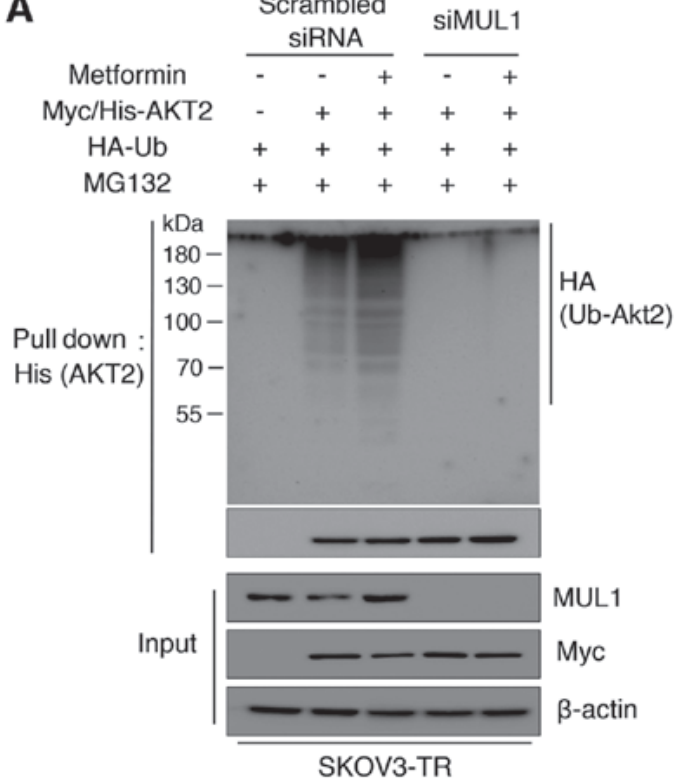

C

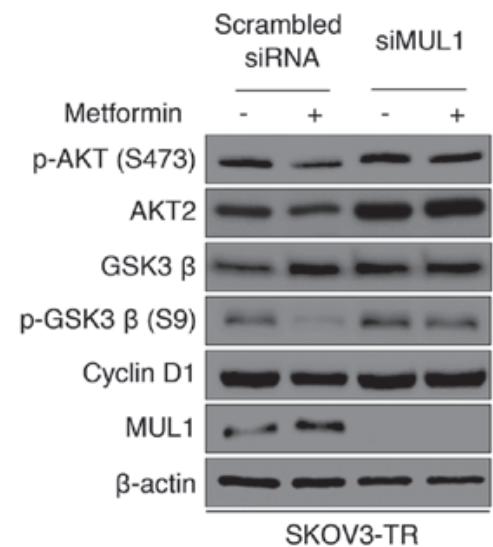

B
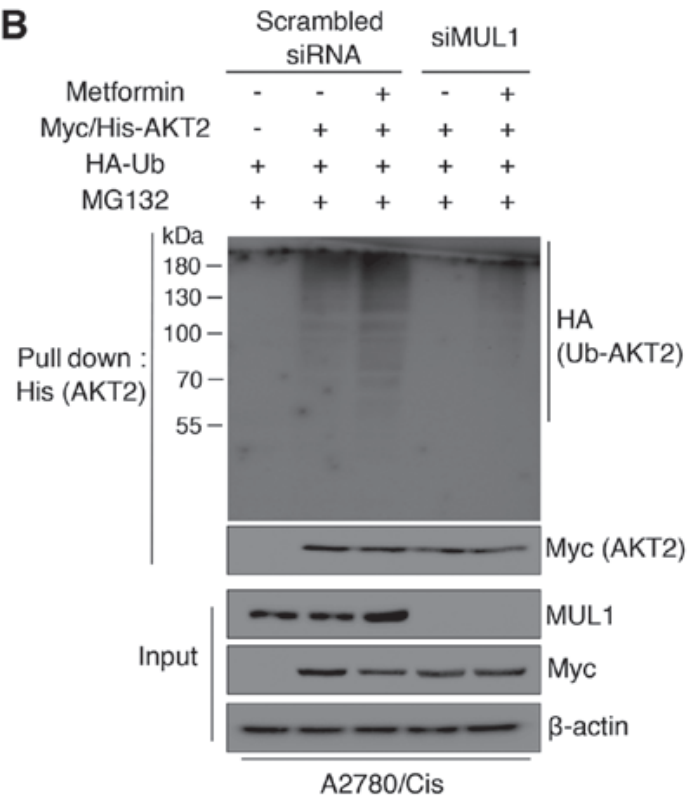

D

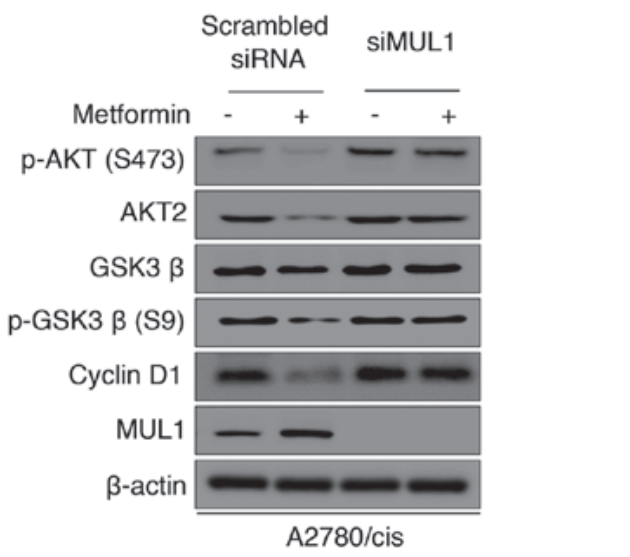

Figure 5. Metformin-induced MUL1 expression promotes AKT degradation in a proteasomal-dependent manner and regulates the AKT downstream pathway. (A) Metformin-induced AKT ubiquitination was mediated by MUL1 in SKOV3-TR and (B) A2780/cis cells. Cells were transfected with AKT-Myc/His and HA-Ub plasmid with scrambled siRNA or siMUL1. Following overnight incubation, cells were treated with $1 \mu \mathrm{M}$ MG132 for $24 \mathrm{~h}$ after exposure to metformin for $48 \mathrm{~h}$. His-pull down assay was then performed using Ni-NTA beads, and the samples were analyzed by immunoblotting with the indicated antibodies (C) MUL1 knockdown inhibited metformin-induced AKT downregulation in SKOV3-TR and (D) A2780/cis cells, which were transfected with 100 pmol scrambled siRNA or siMUL1 followed by metformin treatment for $72 \mathrm{~h}$. Expression levels of indicated proteins were analyzed by immunoblotting. $\beta$-actin was used as a loading control. Samples were derived from the same experiment and gels/blots were processed in parallel. MUL1, mitochondrial E3 ubiquitin protein ligase 1; AKT, AKT serine/threonine kinase; si, small interfering; Ub, ubiquitin; p-, phosphorylated; GSK3 $\beta$, glycogen synthase kinase $3 \beta$.

lines (29). Further studies are required to assess whether the effect of metformin is dependent on inflammatory signaling, as there is presently no functional evidence that MUL1 regulates inflammatory signaling in cancer cells.

Metformin, a widely used drug for the treatment of type 2 diabetes with relatively low side effects $(7,8)$, has attracted much attention in oncology owing to its anticancer activities (14-18). Although the exact mechanisms underlying the effects of metformin have not been completely elucidated, the most well-known mechanism is activation and phosphorylation of AMPK by inhibiting the activity of mitochondrial complex I $(11,12)$. The present study demonstrated that treatment with metformin distinctly upregulated MUL1 expression and downregulated AKT and its downstream targets GSK $3 \beta$ and cyclin D1. However, the p-AMPK levels remained unchanged, suggesting that the anticancer and chemosensitization effects of metformin are independent of the AMPK-mediated pathway. Recent accumulating evidence suggests that the anticancer activities of metformin are mediated by not only AMPK-dependent but also -independent pathways. Metformin decreases the expression levels of cyclin D1, which is an important regulator of cell cycle progression, in the absence of AMPK (42). In addition, the antiproliferative effect of metformin is mediated by AMPK-independent inhibition of mammalian target of rapamycin complex 1 (mTORC1) signaling, which has been implicated in cancer progression (43). Based on these reports, the current findings suggest that AMPK activation is not essential for the anticancer and chemosensitization effects of metformin on drug-resistant ovarian cancer cells.

In summary, the present findings indicate that metformin inhibited the growth and proliferation of drug-resistant ovarian cancer cells, which was mediated by MUL1 expression and the subsequent AKT degradation. Additionally, metformin 
A

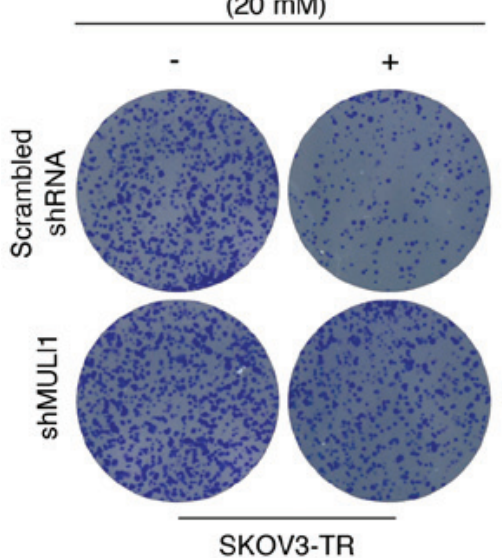

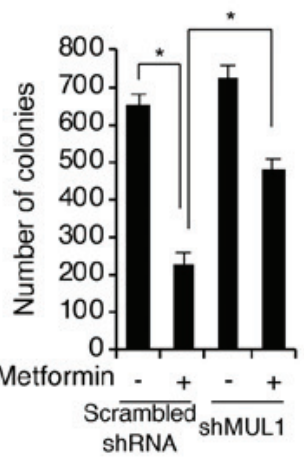
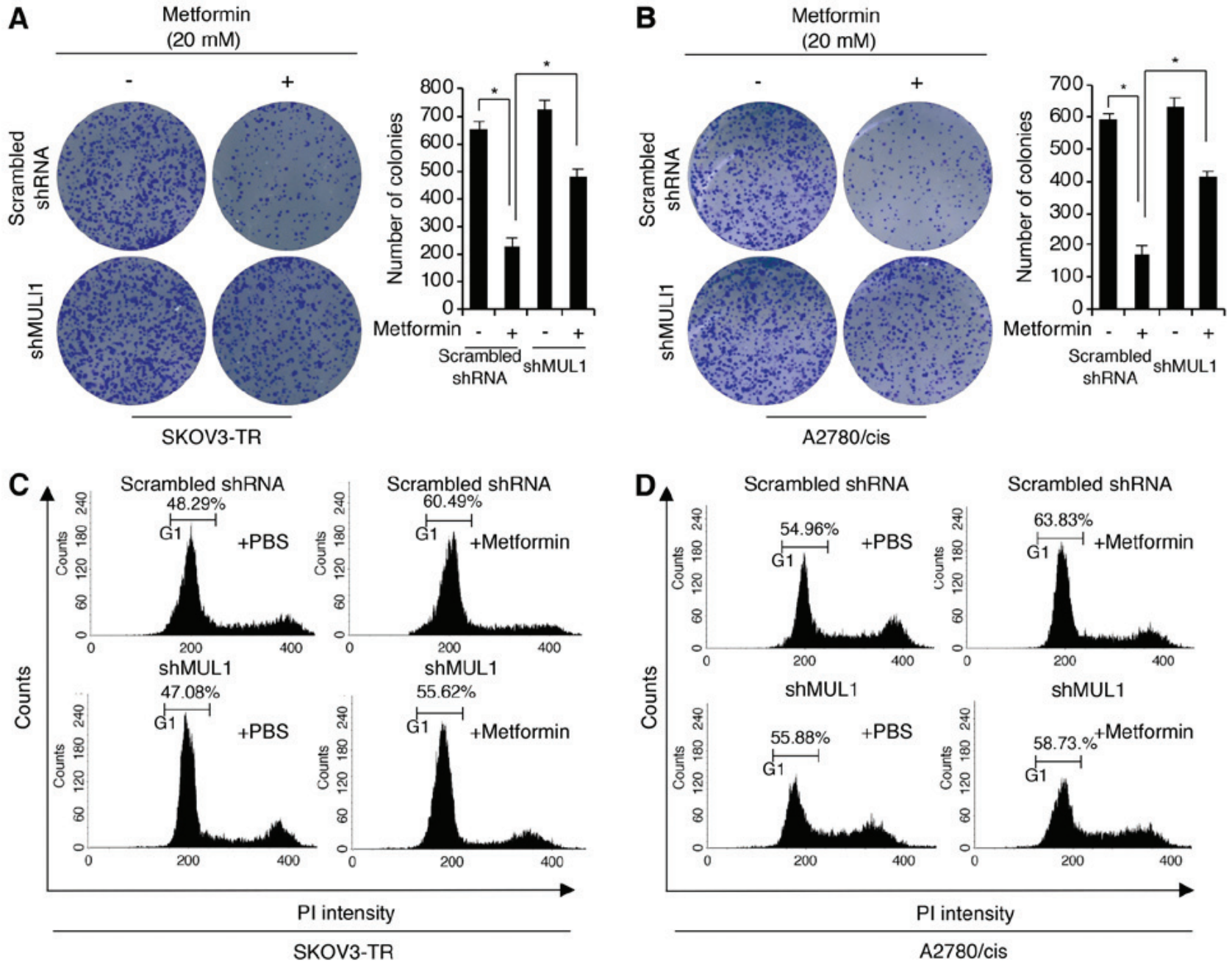

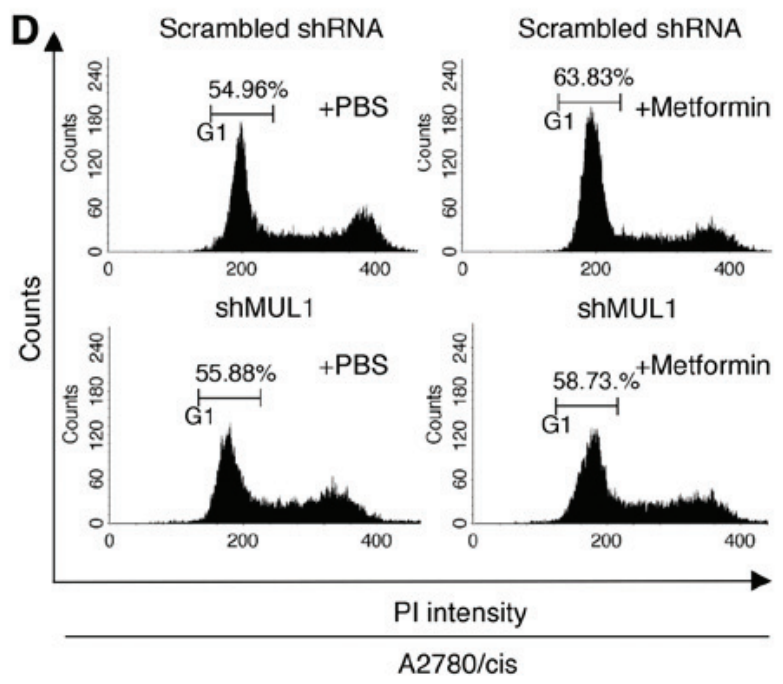

Figure 6. Knockdown of MUL1 decreases the effects of metformin on cell growth and colony formation of chemoresistant ovarian cancer cell lines. (A) MUL1 knockdown by shRNA inhibited the effect of metformin on clonogenic growth in SKOV3-TR and (B) A2780-cis cells. Colonies were imaged (left panel) and counted (right) 14 days after seeding using a standard clonogenic assay. (C) MUL1 knockdown inhibited metformin-induced cell cycle arrest in SKOV3-TR and (D) A2780-cis cells. Cells expressing Scrambled control shRNA or shMUL1 were treated with $20 \mathrm{mM}$ metformin for $72 \mathrm{~h}$, and the cells were evaluated using PI staining and flow cytometry analysis. The \% of cells per total in the G1 phase is noted in the plots. ${ }^{*} \mathrm{P}<0.05$ with comparisons indicated by brackets. MUL1, mitochondrial E3 ubiquitin protein ligase 1; sh, short hairpin; PI, propidium iodide.

promoted the chemosensitization in a MUL1-dependent and AMPK-independent manner. To the best of our knowledge, this is the first study to elucidate the promoting effect and cellular mechanism of metformin and its chemosensitizing potential in drug-resistant ovarian cancer cells.

\section{Acknowledgements}

We thank all the members of our research group for their support and advice during this study.

\section{Funding}

This study resulted from the Konkuk University research support program.

\section{Availability of data and materials}

All data generated or analysed during this study are included in this published article.

\section{Authors' contributions}

JL, SA and SB performed the experiments and wrote the manuscript. JHJ and KK participated in the design of the study and performed the statistical analysis. JYK and ISA analyzed and interpreted the data. SA and SB conceived the study, and participated in its design and coordination and helped to draft manuscript.

\section{Ethics approval and consent to participate}

Not applicable.

\section{Patient consent for publication}

Not applicable.

\section{Competing interests}

The authors declare that they have no competing interests. 


\section{References}

1. McGuire S: World Cancer Report 2014. Geneva, Switzerland: World Health Organization, International Agency for Research on Cancer, WHO Press, 2015. Adv Nutr 7: 418-419, 2016.

2. Engel J, Eckel R, Schubert-Fritschle G, Kerr J, Kuhn W, Diebold J, Kimmig R, Rehbock J and Hölzel D: Moderate progress for ovarian cancer in the last 20 years: Prolongation of survival, but no improvement in the cure rate. Eur J Cancer 38: 2435-2445, 2002.

3. Beaufort CM, Helmijr JC, Piskorz AM, Hoogstraat M, Ruigrok-Ritstier K, Besselink N, Murtaza M, van IJcken WF, Heine AA, Smid M, et al: Ovarian cancer cell line panel (OCCP): Clinical importance of in vitro morphological subtypes. PLoS One 9: e103988, 2014.

4. Banno K, Yanokura M, Iida M, Adachi M, Nakamura K, Nogami Y, Umene K, Masuda K, Kisu I, Nomura H, et al: Application of microRNA in diagnosis and treatment of ovarian cancer. BioMed Res Int 2014: 232817, 2014.

5. Muggia FM: Relevance of chemotherapy dose and schedule to outcomes in ovarian cancer. Semin Oncol 31 (Suppl 15): 19-24, 2004.

6. Agarwal R and Kaye SB: Ovarian cancer: Strategies for overcoming resistance to chemotherapy. Nat Rev Cancer 3: 502-516, 2003.

7. Hundal RS, Krssak M, Dufour S, Laurent D, Lebon V, Chandramouli V, Inzucchi SE, Schumann WC, Petersen KF, Landau BR, et al: Mechanism by which metformin reduces glucose production in type 2 diabetes. Diabetes 49: 2063-2069, 2000.

8. Cao J, Meng S, Chang E, Beckwith-Fickas K, Xiong L, Cole RN, Radovick S, Wondisford FE and He L: Low concentrations of metformin suppress glucose production in hepatocytes through AMP-activated protein kinase (AMPK). J Biol Chem 289: 20435-20446, 2014.

9. McCreight LJ, Bailey CJ and Pearson ER: Metformin and the gastrointestinal tract. Diabetologia 59: 426-435, 2016.

10. Wheaton WW, Weinberg SE, Hamanaka RB, Soberanes S, Sullivan LB, Anso E, Glasauer A, Dufour E, Mutlu GM, Budigner GS, et al: Metformin inhibits mitochondrial complex I of cancer cells to reduce tumorigenesis. eLife 3: e02242, 2014.

11. Musi N, Hirshman MF, Nygren J, Svanfeldt M, Bavenholm P, Rooyackers O, Zhou G, Williams on JM, Ljunqvist O, Efendic S, et al: Metformin increases AMP-activated protein kinase activity in skeletal muscle of subjects with type 2 diabetes. Diabetes 51: 2074-2081, 2002.

12. Stephenne X, Foretz M, Taleux N, van der Zon GC, Sokal E, Hue L, Viollet B and Guigas B: Metformin activates AMP-activated protein kinase in primary human hepatocytes by decreasing cellular energy status. Diabetologia 54: 3101-3110, 2011.

13. Viollet B, Horman S, Leclerc J, Lantier L, Foretz M, Billaud M, Giri S and Andreelli F: AMPK inhibition in health and disease. Crit Rev Biochem Mol Biol 45: 276-295, 2010.

14. Kato K, Gong J, Iwama H, Kitanaka A, Tani J, Miyoshi H, Nomura K, Mimura S, Kobayashi M, Aritomo Y, et al: The antidiabetic drug metformin inhibits gastric cancer cell proliferation in vitro and in vivo. Mol Cancer Ther 11: 549-560, 2012.

15. Fujihara S, Kato K, Morishita A, Iwama H, Nishioka T, Chiyo T, Nishiyama N, Miyoshi H, Kobayashi M, Kobara H, et al: Antidiabetic drug metformin inhibits esophageal adenocarcinoma cell proliferation in vitro and in vivo. Int $\mathrm{J}$ Oncol 46 2172-2180, 2015.

16. Nangia-Makker P, Yu Y, Vasudevan A, Farhana L, Rajendra SG, Levi E and Majumdar AP: Metformin: A potential therapeutic agent for recurrent colon cancer. PLoS One 9: e84369, 2014.

17. Davies G, Lobanova L, Dawicki W, Groot G, Gordon JR, Bowen M, Harkness T and Arnason T: Metformin inhibits the development, and promotes the resensitization, of treatment-resistant breast cancer. PLoS One 12: e0187191, 2017.

18. Dowling RJ, Niraula S, Stambolic V and Goodwin PJ: Metformin in cancer: Translational challenges. J Mol Endocrinol 48 : R31-R43, 2012.

19. Huang $J$ and Manning BD: The TSC1-TSC2 complex: A molecular switchboard controlling cell growth. Biochem J 412: 179-190, 2008

20. Lien EC, Dibble CC and Toker A: PI3K signaling in cancer: Beyond AKT. Curr Opin Cell Biol 45: 62-71, 2017.

21. Zakikhani M, Blouin MJ, Piura E and Pollak MN: Metformin and rapamycin have distinct effects on the AKT pathway and proliferation in breast cancer cells. Breast Cancer Res Treat 123: 271-279, 2010
22. Zhang J, Li G, Chen Y, Fang L, Guan C, Bai F, Ma M, Lyu J and Meng QH: Metformin inhibits tumorigenesis and tumor growth of breast cancer cells by upregulating miR-200c but downregulating AKT2 expression. J Cancer 8: 1849-1864, 2017.

23. Liu Y, Zhang Y, Jia K, Dong Y and Ma W: Metformin inhibits the proliferation of A431 cells by modulating the PI3K/Akt signaling pathway. Exp Ther Med 9: 1401-1406, 2015.

24. Rattan R, Giri S, Hartmann LC and Shridhar V: Metformin attenuates ovarian cancer cell growth in an AMP-kinase dispensable manner. J Cell Mol Med 15: 166-178, 2011.

25. Fresno Vara JA, Casado E, de Castro J, Cejas P, Belda-Iniesta C and González-Barón M: PI3K/Akt signalling pathway and cancer. Cancer Treat Rev 30: 193-204, 2004.

26. Bae S, Kim SY, Jung JH, Yoon Y, Cha HJ, Lee H, Kim K, Kim J, An IS, Kim J, et al: Akt is negatively regulated by the MULAN E3 ligase. Cell Res 22: 873-885, 2012.

27. Livak KJ and Schmittgen TD: Analysis of relative gene expression data using real-time quantitative PCR and the $2(-\Delta \Delta \mathrm{C}(\mathrm{T}))$ method. Methods 25: 402-408, 2001

28. Kim NY, Lee HY and Lee C: Metformin targets Axl and Tyro3 receptor tyrosine kinases to inhibit cell proliferation and overcome chemoresistance in ovarian cancer cells. Int J Oncol 47: 353-360, 2015

29. Dos Santos Guimarães I, Ladislau-Magescky T, Tessarollo NG, Dos Santos DZ, Gimba ER, Sternberg C, Silva IV and Rangel LB: Chemosensitizing effects of metformin on cisplatin- and paclitaxel-resistant ovarian cancer cell lines. Pharmacol Rep 70: 409-417, 2018.

30. Karnevi E, Said K, Andersson R and Rosendahl AH: Metformin-mediated growth inhibition involves suppression of the IGF-I receptor signalling pathway in human pancreatic cancer cells. BMC Cancer 13: 235, 2013.

31. Suizu F, Hiramuki Y, Okumura F, Matsuda M, Okumura AJ, Hirata N, Narita M, Kohno T, Yokota J, Bohgaki M, et al: The E3 ligase TTC3 facilitates ubiquitination and degradation of phosphorylated Akt. Dev Cell 17: 800-810, 2009.

32. Luo J: Glycogen synthase kinase 3beta (GSK3beta) in tumorigenesis and cancer chemotherapy. Cancer Lett 273: 194-200, 2009.

33. Cross DA, Alessi DR, Cohen P, Andjelkovich M and Hemmings BA: Inhibition of glycogen synthase kinase- 3 by insulin mediated by protein kinase B. Nature 378: 785-789, 1995.

34. Giornelli GH: Management of relapsed ovarian cancer: A review. Springerplus 5: 1197, 2016.

35. Jelovac D and Armstrong DK: Recent progress in the diagnosis and treatment of ovarian cancer. CA Cancer J Clin 61: 183-203, 2011.

36. Sherman-Baust CA, Becker KG, Wood Iii WH, Zhang Y and Morin PJ: Gene expression and pathway analysis of ovarian cancer cells selected for resistance to cisplatin, paclitaxel, or doxorubicin. J Ovarian Res 4: 21, 2011.

37. Banno E, Togashi Y, de Velasco MA, Mizukami T, Nakamura Y, Terashima M, Sakai K, Fujita Y, Kamata K, Kitano M, et al: Clinical significance of Akt2 in advanced pancreatic cancer treated with erlotinib. Int J Oncol 50: 2049-2058, 2017.

38. Cheung M and Testa JR: Diverse mechanisms of AKT pathway activation in human malignancy. Curr Cancer Drug Targets 13: 234-244, 2013.

39. Cassinelli G, Zuco V, Gatti L, Lanzi C, Zaffaroni N, Colombo D and Perego P: Targeting the Akt kinase to modulate survival, invasiveness and drug resistance of cancer cells. Curr Med Chem 20: 1923-1945, 2013.

40. Guerrero-Zotano A, Mayer IA and Arteaga CL: PI3K/AKT mTOR: Role in breast cancer progression, drug resistance, and treatment. Cancer Metastasis Rev 35: 515-524, 2016.

41. Kim SH, Juhnn YS and Song YS: Akt involvement in paclitaxel chemoresistance of human ovarian cancer cells. Ann NY Acad Sci 1095: 82-89, 2007.

42. Ben Sahra I, Laurent K, Loubat A, Giorgetti-Peraldi S, Colosetti P, Auberger P, Tanti JF, Le Marchand-Brustel Y and Bost F: The antidiabetic drug metformin exerts an antitumoral effect in vitro and in vivo through a decrease of cyclin D1 level. Oncogene 27: 3576-3586, 2008.

43. Kalender A, Selvaraj A, Kim SY, Gulati P, Brûlé S, Viollet B, Kemp BE, Bardeesy N, Dennis P, Schlager JJ,et al: Metformin, independent of AMPK, inhibits mTORC1 in a rag GTPase-dependent manner. Cell Metab 11: 390-401, 2010. 